\title{
Brain tumor surgery in the elderly: a single institution experience of short-term outcome-a retrospective case study
}

\author{
Mostafa F. Tantawy ${ }^{*}$ a and Wael M. Nazim
}

\begin{abstract}
Background: There is an evolving concern in the management of brain tumors in the elderly. The number of elderly people (aged 65 years or more) increases progressively, and there is a considerable percent of brain tumors affecting this age group. Elderly people may have one or more chronic illnesses that may render cranial surgery of high risk for mortality and morbidity. This study was carried out to evaluate the short-term (30 days) outcome of brain tumor surgery in elderly patients.
\end{abstract}

Results: This is a single-institution retrospective study of elderly patients harboring brain tumors who were managed by surgery. The study included 31 patients between 2014 and 2019. Elective and emergency cases were included. The mean age for the study population was 68.29 years. The mean functional status using the Karnofsky Performance Scale (KPS) changed from 58.06 before surgery to 70 after surgery. Meningioma grade I and glioblastoma multiforme (GBM) were the most common neoplasms, 41.9 and $29 \%$, respectively. There was a statistically significant relationship between the mortality and GBM $(P$ value $<0.05)$ while there was no correlation with concomitant diseases, KPS, or extent of resection ( $P$ value $>0.05$ ). Preoperative concomitant diseases were found in 16 patients. Mortality occurred in 11 cases (35.4\%).

Conclusions: Old age by itself should not be a risk factor alone for increasing mortality or morbidity in cranial surgery for patients with brain tumors. Glioblastoma in old patients with poor KPS carries a significant risk for mortality. Further studies with a larger number of patients and inclusion of more variables are required.

Keywords: Brain tumor, Elderly, Geriatric, Glioblastoma, Meningioma

\section{Background}

The attitude regarding the management of brain tumors in the elderly has become more aggressive. This occurs due to the advances in molecular biology of brain tumors in the geriatric population. As the overall prognosis is still poor, more research and studies seeking more effective management are ongoing [1].

Age-related mortality rates show that increasing mortality rates of primary brain tumors in the elderly are directly proportional to the increase of this population size. Malignant gliomas, especially glioblastoma multiforme, are the

* Correspondence: moustaffkry@med.bsu.edu.eg

Neurosurgery Department, Faculty of Medicine, Beni-Suef University, Beni-Suef, Egypt

Springer Open most common primary brain tumors in the geriatric population [2].

Many factors affect the management of brain tumors in the elderly. Multiple comorbidities and poor overall health status may represent a significant challenge in managing elderly patients with brain tumors. Moreover, old age is a well-known prognostic factor which is associated with worse survival because of tumor grade. Most primary brain tumors in the geriatric population have no available accepted standard treatment [3].

In this monocentric study, the aim is to present our experience regarding the short-term clinical outcome and older patients ( $\geq 65$ years) with brain tumors treated with surgical excision to evaluate the advantages and

(c) The Author(s). 2021 Open Access This article is licensed under a Creative Commons Attribution 4.0 International License, which permits use, sharing, adaptation, distribution and reproduction in any medium or format, as long as you give appropriate credit to the original author(s) and the source, provide a link to the Creative Commons licence, and indicate if changes were made. The images or other third party material in this article are included in the article's Creative Commons licence, unless indicated otherwise in a credit line to the material. If material is not included in the article's Creative Commons licence and your intended use is not permitted by statutory regulation or exceeds the permitted use, you will need to obtain permission directly from the copyright holder. To view a copy of this licence, visit http://creativecommons.org/licenses/by/4.0/. 
limitations of cranial surgery for this particular patient group.

\section{Methods}

This was a retrospective study of elderly patients $(\geq 65)$ with brain tumors who were managed by surgery. The study aim and design were approved by the medical and ethical committee of the neurosurgery department at our institute. The study aim was to assess the morbidity and mortality of brain tumor surgery in patients over age 65 and compare our results with the present literature on cranial surgery in the elderly.

Participants are patients more than 65 years old who were diagnosed with brain tumors. All patients were operated upon by excision. This retrospective study was performed on 31 patients aged 65 years or older, with brain tumors, admitted to the neurosurgery department or the intensive care unit of our hospital, between 2014 and 2019. An analysis was made on variables such as age, sex, pathology, the admission Glasgow Coma Scale (GCS) score, comorbidities, complications, and operative data including blood loss, performance status, and mortality.

Blood samples via venipuncture assess white blood cell count, prothrombin time, international normalized ratio (INR), random blood glucose, and liver and kidney functions to ensure all values were within normal limits. Informed consent was provided by all patients.

The archive of our institute of the neurosurgery department was reviewed for all cases diagnosed with brain tumors and resected at our department between May 2014 and November 2019. The end of the inclusion period was chosen to allow an interval of 1 month between the date of surgery and the date of data collection (January 2020) to detect the perioperative mortality and complications. In all cases, surgery was indicated for the treatment of space-occupying and/or symptomatic lesions in the absence of contraindications against either microsurgery or anesthesia. These contraindications included a life expectancy of only months due to another malignant neoplasm or newly diagnosed life-threatening cardiovascular events. The tumor histopathological type and grading 2007 WHO criteria were determined from neuropathological reports. Baseline medical data, including patients' sex and age at the time of surgery, tumor location, and extent of resection, were obtained from medical and operative reports in each individual case. Tumor location was classified as falx, convexity, sphenoid ridge, petroclival, and posterior fossa. Maximum safely achievable tumor resection/reduction was performed in all patients. Unless contraindications were present (low KPS or refusal by the patients), adjuvant radiation therapy was recommended in all cases of grade III and subtotally resected.
As is standard in our institute, routine postoperative care included follow-up clinical examinations with CT scan with contrast. Gadolinium-enhanced MRI was done if further evaluation was needed. Images were analyzed for tumor progression or residual by a team of at least 2 independent observers, including 1 neurosurgeon and 1 radiologist (or neuroradiologist).

Data were statistically described in terms of mean \pm standard deviation $( \pm \mathrm{SD})$, median and range, or frequencies (number of cases) and percentages when appropriate. Comparison of mortality between the study groups was done using the chi-square $\left(\chi^{2}\right)$ test. The exact test was used instead when the expected frequency is less than 5. For comparing KPS pre versus post, the McNemar test was performed. Two-sided $P$ values less than 0.05 were considered statistically significant. All statistical calculations were done using the computer program IBM SPSS (Statistical Package for the Social Science; IBM Corp, Armonk, NY, USA) release 22 for Microsoft Windows.

The functional impairment before and after surgery was assessed by using the Karnofsky Performance Scale Index. This can be used to compare the effectiveness of different therapies and to assess the prognosis in individual patients. The lower the KPS, the worse the survival for most serious illnesses.

\section{Results}

The mean age for the study population was 68.29 , the mean operative time was 4.26 , the mean tumor volume was 122.94, and the mean blood loss was 590.32 cc. A summary of the clinical data is shown in Table 1. There was a statistically significant relationship between mortality and GBM as the $P$ value was less than 0.05 . A summary of the oncological patterns in our study is shown in Table 2.

There was no statistically significant relationship between the mortality and KPS state pre as the $P$ value was more than 0.05 (Table 3 ). There was no statistically significant relationship between mortality and concomitant disease as the $P$ value was more than 0.05 .

Although there was a clinically significant improvement in the KPS state, there was no statistically significant relationship between the KPS state post and KPS state pre as the $P$ value was more than 0.05 . This may be due to the small sample size (Table 4). There was no statistically significant relationship between mortality and GTR as the $P$ value was more than 0.05 (Table 5).

In our study, there were 12 females and 19 males. The KPS state pre was 70 or more in 14 patients. Seventeen patients have KPS state pre less than 70 . There were 11 cases of convexity meningioma, 3 cases of parasagittal meningioma, 2 cases of petroclival meningioma, 13 cases 
Table 1 The age, operative data, and the perioperative GCS and KPS

\begin{tabular}{|c|c|c|c|c|c|c|c|c|}
\hline & Age (years) & GCS & KPS pre & Operative time & Complaint duration & Blood loss & KPS post & Post GCS \\
\hline Mean & 68.29 & 13.81 & 58.06 & 4.26 & 10.81 & 590.32 & 70.00 & 14.03 \\
\hline$N$ & 31 & 31 & 31 & 31 & 31 & 31 & 31 & 31 \\
\hline SD & 4.228 & 2.344 & 21.513 & 0.815 & 11.867 & 262.177 & 27.325 & 2.415 \\
\hline Median & 68.00 & 15.00 & 60.00 & 4.00 & 5.00 & 600.00 & 80.00 & 15.00 \\
\hline Minimum & 62 & 5 & 10 & 3 & 1 & 100 & 10 & 5 \\
\hline Maximum & 85 & 15 & 90 & 6 & 40 & 1000 & 100 & 15 \\
\hline
\end{tabular}

Values are expressed as mean \pm SD

KPS Karnofsky Performance Scale, N number, SD standard deviation, GCS: Glasgow Coma Scale

of cases supratentorial intraaxial, one case of posterior fossa mass, and one case of sphenoid wing meningioma.

Concerning the associated morbidity, 3 patients were hypertensive, and 6 patients were diabetic. History of hepatitis $\mathrm{C}$ virus was present in 5 patients. Ischemic heart disease was present in one patient. One patient was diabetic and hypertensive with ischemic heart disease.

The KPS state post was 70 or more in 20 patients. Eleven patients have KPS state pre less than 70. Gross total resection was done in 27 cases, subtotal resection was done in 3 cases, and debulking was done in one case only. Concomitant disease was present in 16 cases, and the mortality percent was $35.5 \%$ (11 patients).

\section{Discussion}

With the increasing age of the population and availability of diagnostic tools, neurosurgeons are faced with an increasing number of brain tumors in old people. The incidence of brain tumors (whether primary or secondary) increases with the advancement of age. Although there is appreciable and ongoing improvement in the knowledge and techniques in cranial surgery, neuro-anesthesia, and perioperative intensive care, nevertheless, increasing age deserves special care due to the frailty of patients and the higher incidence of associated diseases that might increase the risk of morbidity and mortality [1-3].

This is a single institution retrospective analysis of the postoperative outcome (30 days) in relation to preoperative risk factors (KPS and associated diseases) and postoperative risk factors (extent of resection, tumor pathology, KPS, and complications) in elderly patients who underwent cranial surgery for brain tumors in the absence of advanced intraoperative equipment.

Our institution is a tertiary referral center serving a district of more than 3 million mostly rural people. It is a dedicated neurosurgical unit, started work since 2014.

All patients underwent microsurgical removal of their brain tumors aiming at total excision whenever possible without affecting surrounding neural structures. This was in the absence of advanced equipment like intraoperative neuromonitoring, navigation, and ICP monitoring in the ICU.

The definition of elderly is not uniform in the literature, starting from 60 years old to 80 in some literatures $[1,4-6]$. We stick to the WHO definition of the elderly as those who are 65 years and older $[7,8]$.

Elderly patients have poor fitness, take medications for chronic diseases, and liable to depression when diagnosed to have brain tumors. There is a debate whether advanced age is to be considered a poor risk factor by itself even in other subspecialties $[1,3,5,9,10]$. Some studies denied the effect of age on the outcome of brain tumor surgery [3, 4, 11-13]. Others favored avoiding surgery above the age of 70 [3].

Several studies showed that the preoperative functional status has a significant impact on the outcome more than the effect of age $[3,13,14]$. The cutoff value of KPS

Table 2 The relationship between mortality and pathology

\begin{tabular}{|c|c|c|c|c|c|c|c|c|c|}
\hline & & & \multicolumn{7}{|l|}{ Pathology } \\
\hline & & & Anaplastic astrocytoma & $\begin{array}{l}\text { Atypical } \\
\text { meningioma G2 }\end{array}$ & GBM & Glioma G2 & Gliosarcoma & Meningioma G1 & Mets \\
\hline \multirow[t]{6}{*}{ Death } & No & Count & 2 & 4 & 2 & 1 & 0 & 11 & 0 \\
\hline & & $\%$ within death & $10.0 \%$ & $20.0 \%$ & $10.0 \%$ & $5.0 \%$ & $0.0 \%$ & $55.0 \%$ & $0.0 \%$ \\
\hline & & $\%$ within pathology & $100.0 \%$ & $100.0 \%$ & $22.2 \%$ & $100.0 \%$ & $0.0 \%$ & $84.6 \%$ & $0.0 \%$ \\
\hline & Yes & Count & 0 & 0 & 7 & 0 & 1 & 2 & 1 \\
\hline & & $\%$ within death & $0.0 \%$ & $0.0 \%$ & $63.6 \%$ & $0.0 \%$ & $9.1 \%$ & $18.2 \%$ & $9.1 \%$ \\
\hline & & $\%$ within pathology & $0.0 \%$ & $0.0 \%$ & $77.8 \%$ & $0.0 \%$ & $100.0 \%$ & $15.4 \%$ & $100.0 \%$ \\
\hline
\end{tabular}

G grade, GBM glioblastoma multiforme, Mets metastasis 
Table 3 The relationship between mortality and KPS state pre

\begin{tabular}{|c|c|c|c|c|c|}
\hline & & & \multicolumn{2}{|c|}{ KPS state pre } & \multirow[t]{2}{*}{ Total } \\
\hline & & & $<70$ & 70 or more & \\
\hline \multirow[t]{6}{*}{ Death } & No & Count & 11 & 9 & 20 \\
\hline & & $\%$ within death & $55.0 \%$ & $45.0 \%$ & $100.0 \%$ \\
\hline & & $\%$ within KPS state pre & $64.7 \%$ & $64.3 \%$ & $64.5 \%$ \\
\hline & Yes & Count & 6 & 5 & 11 \\
\hline & & $\%$ within death & $54.5 \%$ & $45.5 \%$ & $100.0 \%$ \\
\hline & & $\%$ within KPS state pre & $35.3 \%$ & $35.7 \%$ & $35.5 \%$ \\
\hline \multirow[t]{3}{*}{ Total } & \multicolumn{2}{|c|}{ Count } & 17 & 14 & 31 \\
\hline & \multicolumn{2}{|c|}{$\%$ within death } & $54.8 \%$ & $45.2 \%$ & $100.0 \%$ \\
\hline & \multicolumn{2}{|c|}{$\%$ within KPS state pre } & $100.0 \%$ & $100.0 \%$ & $100.0 \%$ \\
\hline
\end{tabular}

is 70 or 80 in some literature below which there will be significant poor outcomes after surgery $[14,15]$.

On the contrary, there was no significant correlation between preoperative KPS and the outcome. While there was a clinical improvement in postoperative KPS, this was not true statistically, possibly because of the small number of patients included.

In this study, not all the cases were elective; some of our patients were admitted on an emergency basis due to intracranial pressure rise from the mass effect of the tumor or the associated edema. Surgery was carried out to decrease the ICP and obtain pathology. We think this is an important point as many literatures that discussed the subject of cranial surgery in the elderly included only elective cases and came to conclude the safety of surgery in selected elective cases $[5,15]$. Other studies that involved emergency cases found increased poor outcomes within these cases [15].

The associated medical comorbidity is reported in several studies to be associated with poor outcomes [3, 13, 14]. Although 16 of our patients (51.6\%) had preoperative medical problems, this was not associated statistically with postoperative mortality. The severity of those problems was not studied, and this could explain the negative relationship.

Meningioma grade I then GBM accounted for most of the lesions like the publications, although GBM is more common in this age group in the literature $[1,16]$. This is possible because of the limited number of patients in this series. To a lesser extent, there were fewer cases of atypical meningioma, anaplastic astrocytoma, grade II glioma, and metastasis.

The incidence of GBM is increasing as age advances, and the overall survival is short, and it is even shorter in the elderly. The relative risk is $3-4$ times in old patients compared to the young $[6,17,18]$. We are not discussing here the adjuvant therapy, but the short-term outcome of surgery which is considered the first line of treatment for accessible lesions causing neurological deficit $[6,16]$.

The incidence of meningioma rises after the age of 65 also, and most of the cases are grade I $[15,19]$. Surgery is considered safe even in very old cases more than 80 years old, so the long preoperative performance is good [20].

We tried to get out of the maximum tumor volume without jeopardizing tumor tissue as all the lesions had a significant size and/or edema causing compression on the surroundings. Gross total resection was achieved in most of the cases. This was proved by intraoperative microscopic total excision in conjunction with postoperative radiology. This agrees with studies that favor maximum tumor resection as this is in favor with better survival and lower risk for mortality and morbidity [21-27].

There was a significant correlation between GBM and mortality within 1 month. The mortality rate was higher than the reported in the literature. We think this is because not all cases were elective and so the lower preoperative KPS of GBM patients (mean around 50).

Table 4 The relationship between KPS state post and KPS state pre

\begin{tabular}{|c|c|c|c|c|}
\hline & & & \multicolumn{2}{|c|}{ KPS state pre } \\
\hline & & & $<70$ & 70 or more \\
\hline \multirow[t]{8}{*}{ KPS state post } & $<70$ & Count & 7 & 4 \\
\hline & & $\%$ within KPS state post & $63.6 \%$ & $36.4 \%$ \\
\hline & & $\%$ within KPS state pre & $41.2 \%$ & $28.6 \%$ \\
\hline & & $\%$ of total & $22.6 \%$ & $12.9 \%$ \\
\hline & 70 or more & Count & 10 & 10 \\
\hline & & $\%$ within KPS state post & $50.0 \%$ & $50.0 \%$ \\
\hline & & $\%$ within KPS state pre & $58.8 \%$ & $71.4 \%$ \\
\hline & & $\%$ of total & $32.3 \%$ & $32.3 \%$ \\
\hline
\end{tabular}


Table $\mathbf{5}$ The relationship between mortality and GTR

\begin{tabular}{|c|c|c|c|c|c|}
\hline & & & GTR & & \\
\hline & & & Debulking & Subtotal & Total \\
\hline Death & No & Count & 0 & 2 & 18 \\
\hline & & $\%$ within death & $0.0 \%$ & $10.0 \%$ & $90.0 \%$ \\
\hline & & $\%$ within GTR & $0.0 \%$ & $66.7 \%$ & $66.7 \%$ \\
\hline & Yes & Count & 1 & 1 & 9 \\
\hline & & $\%$ within death & $9.1 \%$ & $9.1 \%$ & $81.8 \%$ \\
\hline & & $\%$ within GTR & $100.0 \%$ & $33.3 \%$ & $33.3 \%$ \\
\hline
\end{tabular}

GTR gross total resection

Not all risk factors were covered in this study. The severity of the concomitant morbidity also was not detailed, although there was no relationship with mortality. The retrospective nature and the limited number of patients also limited the assessment of a larger number of variables. The inclusion of emergency cases prevented the comparison with other studies focusing on elective cases and resulted in a higher number of mortality compared to the literature.

\section{Conclusions}

Old age by itself should not be a risk factor alone for increasing mortality or morbidity in cranial surgery for patients with brain tumors. Glioblastoma in old patients with poor KPS carries a significant risk for mortality. Further prospective studies with a larger number of patients and inclusion of more variables are required.

\section{Abbreviations \\ KPS: Karnofsky Performance Scale; GBM: Glionblastoma multiforme; GCS: Glasgow Coma Scale; INR: International normalized ratio; WHO: World Health Organization; CT: Computerized tomography; MRI: Magnetic resonance imaging; ICP: Intracranial pressure; GTR: Gross total resection}

\section{Acknowledgements}

Not applicable.

\section{Statement of authorship}

The study idea, design, material selection, and outcome assessment were all done by two neurosurgeons, Dr. Wael M. Nazim and Dr. Mostafa Fekry.

\section{Authors' contributions}

MF collected and analyzed the data and wrote the manuscript. WN shared in the writing, review, and preparation of the manuscript for publication. Both authors read and approved the final manuscript.

\section{Funding}

This study is funded by the authors in all aspects (collection, statistical analysis, and writing of the manuscript).

\section{Availability of data and materials}

Data used and analyzed in this study are available from the authors on reasonable request.

\section{Declarations}

\section{Ethics approval and consent to participate}

This work has been approved by the ethics committee in the Department of Neurosurgery, Faculty of Medicine, Beni-Suef University (2014). Reference number is not applicable.
Consent to participate has been approved also by the same committee.

\section{Consent for publication}

Not applicable.

\section{Competing interests}

The authors declare that they have no competing interests.

Received: 13 November 2020 Accepted: 2 July 2021

Published online: 20 July 2021

\section{References}

1. Seddighi A, Vaezi M, Naimian S, Yourdkhani F, Seddighi AS, Mellati O, et al. Brain tumors in elderly. Int Clin Neurosci J. 2015;2:55.

2. Philippon J. Tumeurs cérébrales du sujet âgé [Brain tumors in the elderly]. Psychol Neuropsychiatr Vieil. 2004;2(1):29-33.

3. Johans SJ, Garst JR, Burkett DJ, Grahnke K, Martin B, Ibrahim TF, et al. Identification of preoperative and intraoperative risk factors for complications in the elderly undergoing elective craniotomy. World Neurosurg. 2017;107:216-25. https://doi.org/10.1016/j.wneu.2017.07.177.

4. Seicean A, Seicean S, Schiltz NK, Alan N, Jones PK, Neuhauser D, et al. Shortterm outcomes of craniotomy for malignant brain tumors in the elderly. Cancer. 2013;119(5):1058-64. https://doi.org/10.1002/cncr.27851.

5. Schär RT, Tashi S, Branca M, Söll N, Cipriani D, Schwarz C, et al. How safe are elective craniotomies in elderly patients in neurosurgery today? A prospective cohort study of 1452 consecutive cases. J Neurosurg. 2020; 134(4):1113-21.

6. Okada M, Miyake K, Tamiya T. Glioblastoma treatment in the elderly. Neurol Med Chir (Tokyo). 2017:57(12):667-76. https://doi.org/10.2176/nmc.ra.20170009.

7. Singh S, Bajorek B. Defining 'elderly' in clinical practice guidelines for pharmacotherapy. Pharm Pract (Granada). 2014;12(4):489.

8. Ikawa F, Kinoshita Y, Takeda M, Saito T, Yamaguchi S, Yamasaki F, et al. Review of current evidence regarding surgery in elderly patients with meningioma. Neurol Med Chir (Tokyo). 2017;57(10):521-33. https://doi.org/1 0.2176/nmc.ra.2017-0011.

9. Reponen E, Korja M, Niemi T, Silvasti-Lundell M, Hernesniemi J, Tuominen H. Preoperative identification of neurosurgery patients with a high risk of inhospital complications: a prospective cohort of 418 consecutive elective craniotomy patients. J Neurosurg. 2015;123(3):594-604. https://doi.org/10.31 71/2014.11.JNS141970

10. Konglund A, Rogne SG, Lund-Johansen M, Scheie D, Helseth E, Meling TR. Outcome following surgery for intracranial meningiomas in the aging. Acta Neurol Scand. 2013;127(3):161-9. https://doi.org/10.1111/j.1600-0404.2012.01 692.x.

11. Grossman R, Mukherjee D, Chang DC, Purtell M, Lim M, Brem H, et al. Predictors of inpatient death and complications among postoperative elderly patients with metastatic brain tumors. Ann Surg Oncol. 2011;18(2): 521-8. https://doi.org/10.1245/s10434-010-1299-2.

12. Nayak L, Iwamoto FM. Primary brain tumors in the elderly. Curr Neurol Neurosci Rep. 2010;10(4):252-8. https://doi.org/10.1007/s11910-010-0110-x.

13. Rabadán AT, Hernandez D, Eleta M, Pietrani M, Baccanelli M, Christiansen S, et al. Factors related to surgical complications and their impact on the functional status in 236 open surgeries for malignant tumors in a LatinoAmerican hospital. Surg Neurol. 2007;68(4):412-20. https://doi.org/10.1016/j. surneu.2006.11.050.

14. Asano K, Nakano T, Takeda T, Ohkuma H. Risk factors for postoperative systemic complications in elderly patients with brain tumors. Clinical article. J Neurosurg. 2009;111(2):258-64. https://doi.org/10.3171/2008.10.17669.

15. Galhom AE, Madawi AA, Ellabban MM. Surgical outcomes and predictors of complication in elderly patients with meningiomas. Egypt I Neurol Psychiatry Neurosurg. 2018:54(1):1-2.

16. Cohen-Inbar O. Geriatric brain tumor management part II: glioblastoma multiforme. J Clin Neurosci. 2019;67:1-4. https://doi.org/10.1016/j.jocn.2019. 05.064.

17. Minniti G, Lombardi G, Paolini S. Glioblastoma in elderly patients: current management and future perspectives. Cancers. 2019;11(3):336. https://doi. org/10.3390/cancers 11030336 .

18. Snyder J, Walbert T. Managing Glioblastoma in the Elderly Patient: New Opportunities. Oncology (Williston Park). 2017;31 (6):476-83. 
19. Cohen-Inbar O. Geriatric brain tumor management part I: meningioma. J Clin Neurosci. 2019;67:5-9. https://doi.org/10.1016/j.jocn.2019.05.063.

20. Brokinkel B, Holling M, Spille DC, Heß K, Sauerland C, Bleimüller C, et al. Surgery for meningioma in the elderly and long-term survival: comparison with an age-and sex-matched general population and with younger patients. J Neurosurg. 2017;126(4):1201-11. https://doi.org/10.3171/2016.2. JNS152611.

21. Almenawer SA, Badhiwala JH, Alhazzani W, Greenspoon J, Farrokhyar F, Yarascavitch B, et al. Biopsy versus partial versus gross total resection in older patients with high-grade glioma: a systematic review and metaanalysis. Neuro-Oncol. 2015;17(6):868-81. https://doi.org/10.1093/neuonc/ nou349.

22. Brandes AA, Vastola F, Basso U, Berti F, Pinna G, Rotilio A, et al. A prospective study on glioblastoma in the elderly. Cancer. 2003;97(3):657-62. https://doi.org/10.1002/cncr.11097.

23. Babu R, Komisarow JM, Agarwal VJ, Rahimpour S, lyer A, Britt D, et al. Glioblastoma in the elderly: the effect of aggressive and modern therapies on survival. J Neurosurg. 2016;124(4):998-1007. https://doi.org/10.3171/201 5.4.JNS142200.

24. Morgan ER, Norman A, Laing K, Seal MD. Treatment and outcomes for glioblastoma in elderly compared with non-elderly patients: a populationbased study. Curr Oncol. 2017;24(2):e92.

25. Schwartz C, Romagna A, Stefanits H, Zimmermann G, Ladisich B, Geiger P, et al. Risks and benefits of glioblastoma resection in older adults: a retrospective Austrian multicenter study. World Neurosurg. 2020;133:e58391. https://doi.org/10.1016/..wneu.2019.09.097.

26. Bernstein M. Brain tumour surgery in the elderly: a brief reappraisal. Cana J Surg. 1996;39(2):147.

27. Sawaya R, Hammoud M, Schoppa D, Hess KR, Wu SZ, Shi WM, et al. Neurosurgical outcomes in a modern series of 400 craniotomies for treatment of parenchymal tumors. Neurosurg. 1998;42(5):1044-55. https:// doi.org/10.1097/00006123-199805000-00054

\section{Publisher's Note}

Springer Nature remains neutral with regard to jurisdictional claims in published maps and institutional affiliations.

\section{Submit your manuscript to a SpringerOpen ${ }^{\circ}$ journal and benefit from:}

- Convenient online submission

- Rigorous peer review

- Open access: articles freely available online

High visibility within the field

- Retaining the copyright to your article

Submit your next manuscript at $\boldsymbol{\nabla}$ springeropen.com 